\title{
Hafnium silicate dielectrics fabricated by RF magnetron sputtering
}

\author{
L. Khomenkova *,1, X. Portier, P. Marie, F. Gourbilleau \\ CIMAP, CEA/CNRS/ENSICAEN/UCBN, 6 Boulevard du Maréchal-Juin, F-14050 Caen Cedex, France
}

Keywords:

High-k dielectrics; Hafnium

oxide; Hafnium silicate;

RF magnetron sputtering;

\begin{abstract}
A B S T R A C T
Structural and composition properties of hafnium silicate layers fabricated by RF magnetron sputtering were studied by means of spectroscopic ellipsometry, X-ray diffraction, transmission electron microscopy and attenuated total reflection infrared spectroscopy with respect to the deposition parameters and postdeposition annealing treatment. The variation of the deposition conditions allows the temperature of amorphous-crystalline phase transformation of pure hafnium oxide layers to be controlled. It is shown that the silicon incorporation in oxide matrix prevents the formation of interfacial silicon oxide layer and plays a major role in the stability of the structure of hafnium based layers remaining an amorphous state upon annealing at $900-950{ }^{\circ} \mathrm{C}$.
\end{abstract}

\section{Introduction}

High-k oxides are promising for future CMOS devices owing to wide band gap (higher than $5 \mathrm{eV}$ ), good thermal stability on silicon and high permittivity (more than 20), which are vital to overcome the problem of high leakage current [1-5]. Based on thermodynamic studies [6] and band gap measurements [7], hafnium oxide is considered as the best candidate among high-k dielectrics to replace silicon oxide and its oxynitride in CMOS devices. However, the microstructure, optic and electrical properties of ultrathin films depend strongly on the fabrication process, growth conditions and post deposition treatment.

The most widespread techniques for fabrication of ultrathin layers were ALD, CVD and MOCVD [5,8-11]. Unfortunately, lower-temperature methods such as physical vapor deposition [12] and magnetron sputtering [13-16] were not often addressed. It is worth to note that magnetron sputtered $\mathrm{HfO}_{2}$ layers were fabricated by sputtering of pure metallic $\mathrm{Hf}$ cathode either in argon-oxygen gas mixture [13], or in pure argon plasma and then submitted to oxidation. Only in a few cases, the layers were deposited from a pure $\mathrm{HfO}_{2}$ target [14-18].

The use of pure $\mathrm{HfO}_{2}$ as a gate dielectric in the direct contact with Si substrate suffered from the undesirable formation of an interfacial $\mathrm{SiO}_{2}$ layer during deposition or annealing treatment $[1,2]$. To overcome this problem, it was proposed to form Si oxynitride or

\footnotetext{
* Corresponding author. Permanent address: V.Lashkaryov Institute of Semiconductor Physics, NAS Ukraine, 45 Pr. Nauky, 03028 Kyiv, Ukraine. Tel: + 380445257234 E-mail addresses: larysa.khomenkova@ensicaen.fr, khomenkova@rambler.ru (L. Khomenkova), fabrice.gourbilleau@ensicaen.fr (F. Gourbilleau).

1 Tel.: + 33 231452671; fax: + 33231452557 .
}

nitride barrier between high-k material and the Si substrate. Another drawback of pure $\mathrm{HfO}_{2}$ is its low crystallization temperature (about $350-500{ }^{\circ} \mathrm{C}$ ) accompanied usually by a formation of monoclinic phase. At the same time, amorphous films are advantageous because of their lower leakage current, a better homogeneity and, moreover, a higher reproducibility for the electrical properties in comparison with polycrystalline gate dielectric films. The improvement of thermal stability of amorphous $\mathrm{HfO}_{2}$ phase was an issue of numerous investigations. It was shown, for example, in Refs. $[13,19]$ that the incorporation of nitrogen into high-k matrix either during the deposition or post-deposition processing allows amorphous HfON films to be thermally stable up to $1100{ }^{\circ} \mathrm{C}$.

The dielectric properties of $\mathrm{HfO}_{2}$ depend significantly on its microstructure: both amorphous and monoclinic phases exhibit a dielectric constant of $16-20$, but cubic and tetragonal phases have higher relative permittivity (about 28 [20]) and they are preferable in terms of device application. The formation of tetragonal and cubic phases requires an incorporation of cationic dopants in the $\mathrm{HfO}_{2}$ matrix as it was demonstrated both theoretically [21-23] and experimentally [24-26]. Note that the dopants have to be carefully chosen to prevent a significant decrease of the band gap energy and dielectric constant of the material.

The most promising candidate to fulfill these conditions is silicon. Its incorporation into $\mathrm{HfO}_{2}$ matrix results in the formation of pseudobinary alloys such as $\left(\mathrm{HfO}_{2}\right)_{x}\left(\mathrm{SiO}_{2}\right)_{1-x}$. A significant decrease of leakage current and an improvement of thermodynamic stability of this alloy were demonstrated in Refs. $[1-3,27]$. However, the permittivity of this material depends significantly on its composition and in most cases it was found to be less than 10 , whereas higher permittivity values are required for microelectronic applications. Considering the above mentioned discussion, the effect of the silicon 
incorporation on the properties of $\mathrm{HfSiO}$ dielectric materials requires further investigation.

In the present study, $\mathrm{HfO}_{2}$-based thin layers have been fabricated by $\mathrm{RF}$ magnetron sputtering of a pure $\mathrm{HfO}_{2}$ or composed $\mathrm{HfO}_{2}+\mathrm{Si}$ targets in pure argon plasma. The properties of the layers have been analyzed by means of X-ray diffraction, phase-modulated spectroscopic ellipsometry, infrared absorption spectroscopy and high resolution transmission electron microscopy with respect to the deposition conditions and the annealing treatments.

\section{Experimental}

The layers investigated were grown on B-doped (100) oriented Si substrates with a resistivity of $15 \Omega \mathrm{cm}$. The substrates were cleaned in a diluted hydrofluoric solution (10\%) to remove native oxide, dried in nitrogen flow and immediately placed into the vacuum chamber of the deposition setup.

Pure and $\mathrm{Si}$-rich $\mathrm{HfO}_{2}$ layers were grown by RF magnetron sputtering of 4 inches $\mathrm{HfO}_{2}$ target (99.9\%) in pure argon plasma at RF power density $R F P=0.74-1.2 \mathrm{~W} / \mathrm{cm}^{2}$. The substrate temperature was kept at 45 and $100{ }^{\circ} \mathrm{C}$, the total plasma pressure and substrate-cathode distance were fixed at $0.04 \mathrm{mbar}$ and $57 \mathrm{~mm}$, respectively. Si-rich layers were fabricated by the co-sputtering of $\mathrm{HfO}_{2}$ target topped by $\mathrm{Si}$ chips with a surface ratio of $R_{S i}=12 \%$. The latter was estimated as a ratio of the surface of all $\mathrm{Si}$ chips to the total surface of $\mathrm{HfO}_{2}$ target. To study the thermal stability of the layers, an annealing treatment in nitrogen flow in a conventional furnace at different temperatures $T_{A}=600-1100{ }^{\circ} \mathrm{C}$ during $t_{A}=15$ and $30 \mathrm{~min}$ was performed.

Several techniques were used to analyze the properties of the layers. The thickness of the films was analyzed by means of X-ray reflectometry and phase-modulated spectroscopic ellipsometry. Besides, the last technique was used to determine optical parameters of the films. The data were collected by means of a Jobin-Yvon ellipsometer (UVISEL) where the incident light was scanned in the range of $1.5-4.5 \mathrm{eV}$ under an incident angle of $66.3^{\circ}$. The fitting of the experimental data was performed using DeltaPsi2 software [28]. The uncertainty of this method in the estimation of the refractive index is $\Delta n= \pm 0.01$. ATR-FTIR technique was used to control the chemical composition of the layers. The spectra were measured in the range of $600-4000 \mathrm{~cm}^{-1}$ by means of a $60^{\circ} \mathrm{Ge}$ Smart Ark accessory inserted in a Nicolet Nexus spectrometer. X-ray diffraction analysis was performed using a Phillips XPERT HPD Pro device with a $\mathrm{Cu} \mathrm{K}_{\alpha}$ radiation $(\lambda=0.154 \mathrm{~nm})$ at a fixed grazing angle incidence of $0.5^{\circ}$. Cross-sectional specimens were prepared for TEM examination by the standard procedure involving grinding, dimpling and $\mathrm{Ar}^{+}$ion beam thinning until electron transparency. The samples were observed by conventional (CTEM) and high resolution electron microscopy (HRTEM) using a FEG 2010 JEOL instrument, operated at $200 \mathrm{kV}$. Image processing was done with the commercial Digital micrograph GATAN software.

\section{Results}

\subsection{Spectroscopic ellipsometry analysis}

Spectroscopic ellipsometry does not require special environment and can be easily integrated into a semiconductor processing $[29,30]$ as a fast, sensitive and non-destructive method for film characterization. The fitting of the experimental data is usually based on the effective medium approximation (EMA) [29,31]. There are several EMA models (Bruggeman, Maxwell-Garnet, etc.). As for all mean field theories, they fail to predict the properties of a multiphase medium close to the percolation threshold due to its long-range correlation length. They suppose that the macroscopic system is homogeneous (with correlation length below the Lorentz cavity radius) whereas the properties of multiphase system are determined by the properties of its components and their relative fractions. The most considered parameters are conductivity and/or dielectric constant.

In the present work, Bruggeman effective medium approximation (BEMA) is used [31]. To investigate the properties of the as-deposited and annealed layers, a four-phase optical model is applied [18]. It consists of a silicon substrate, an interfacial $\mathrm{SiO}_{2}$ layer, an amorphous HfO-based layer (pure or Si-rich), and a surface rough layer, composed of a mixture of void space and $\mathrm{HfO}_{2}$-based layer. To fit spectroscopic ellipsometry data, the dispersion law for $n$ and $k$ was chosen as described in Ref. [18]. It is based on the Forouhi-Bloomer model elaborated for amorphous semiconductor and insulating materials [32] using an improved parameterization [33]. The model structure and optical properties of the films were optimized by leastsquare refinement approach $\left(\chi^{2}\right)$ from a fitting of the experimental data. As a result, the thickness of HfO-based film (pure or Si-rich) and interfacial $\mathrm{SiO}_{2}$ layer, the dispersion law of refractive index and absorption coefficient were obtained.

The evolution of the refractive index of pure $\mathrm{HfO}_{2}$ and $\mathrm{HfSiO}$ films with the annealing treatment is presented in Fig. 1. As one can see, asdeposited pure $\mathrm{HfO}_{2}$ film demonstrates an $n$ value around 2.03 at 2-eV light energy. The annealing treatment shows a slight decrease of the refractive index down to $n=1.97$ (Fig. 1a, curve 1). Using the Clausius-Mossotti relationship between optical dielectric constant and film density, $\rho$, the latter was estimated with the relative uncertainty of $\leq 5 \%$. As for pure $\mathrm{HfO}_{2}$ films, they were considered to be composed of $\mathrm{HfO}_{6}$ and/or $\mathrm{HfO}_{8}$ unit cells [20] and their density was found to be in the range of $8.0-8.8 \mathrm{~g} / \mathrm{cm}^{3}$. It increased slightly for higher temperatures (Fig. 1b) confirming the data described in Ref. [34].

The as-deposited HfSiO films exhibit the higher $n$ value in comparison with pure $\mathrm{HfO}_{2}$ films, i.e. 2.12 against 2.03 (Fig. 1a) whereas $n$ decreases upon annealing (Fig. 1a). Thus, HfSiO films annealed at $T_{A} \geq 800{ }^{\circ} \mathrm{C}$ exhibit lower $n$ values $(n=1.85)$ than their pure counterparts $(n=1.97)$. Besides, they demonstrate the decrease of the extinction coefficient, $k$, followed by a shift of the "absorption

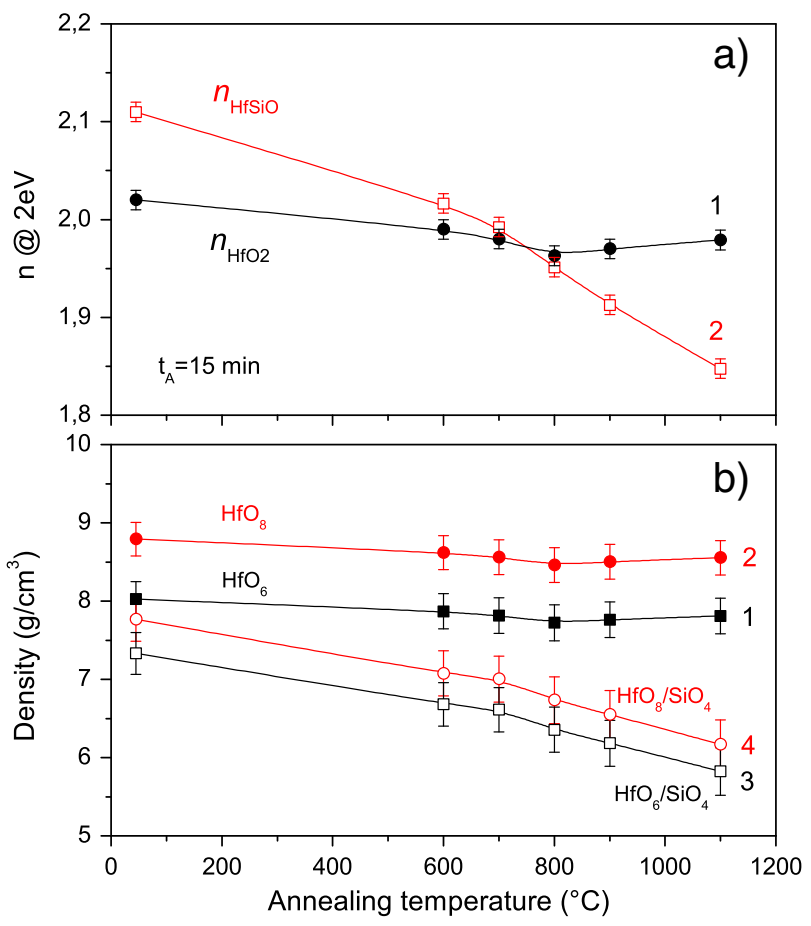

Fig. 1. The evolution of (a) the refractive index, $n$, and (b) the density of the films, $\rho$, with annealing temperature for pure $\mathrm{HfO}_{2}$ and $\mathrm{HfSiO}$ films. The annealing time is $15 \mathrm{~min}$. The density of the $\mathrm{HfO}_{2}$ films is estimated for two unit cells as $\mathrm{HfO}_{6}$ and $\mathrm{HfO}_{8}$, the density of $\mathrm{HfSiO}$ films is presented considering two possible unit cells as $\mathrm{HfO}_{6} / \mathrm{SiO}_{4}$ and $\mathrm{HfO}_{8} / \mathrm{SiO}_{4}$. 
edge" to higher energy side (not shown here). Since the optic model, proposed in the present study, allows the contributions of interfacial $\mathrm{SiO}_{2}$ layer and HfO-based layer to be separated, this means that a decrease of $n$ and $k$ values observed for HfSiO upon annealing is more likely due to structural transformation of HfO-based layer itself rather than due to the increase of the contribution of interfacial $\mathrm{SiO}_{2}$ one. In the case of pure $\mathrm{HfO}_{2}$ films, the formation of voids in film volume can explain the decrease of the refractive index. It could be the same reason for the $n$ evolution in the case of HfSiO films, but the formation of $\mathrm{SiO}_{2}$ phase stimulated by high temperature annealing has also to be taken into account as a cause of the refractive index decrease. Moreover, as we showed earlier [16,17], an annealing at $T_{A}=800^{\circ} \mathrm{C}$ for $15 \mathrm{~min}$ did not lead to the formation of any pores in the $\mathrm{HfSiO}$ volume. Consequently a formation of $\mathrm{SiO}_{2}$ phase could be only the reason of the lowering of the refractive index upon annealing and this can explain the increasing of film transparency.

The density of the HfSiO films was also estimated based on the approach described in Ref. [18]. Similar to the case of pure $\mathrm{HfO}_{2}$ films it was assumed that the $\mathrm{HfO}_{2}$ phase is presented by $\mathrm{HfO}_{6}$ and/or $\mathrm{HfO}_{8}$ unit cells, whereas the $\mathrm{SiO}_{2}$ phase consisted of $\mathrm{SiO}_{4}$ unit cells. The results obtained, considering both possibilities, are presented in Fig. 1b. The film density decreases gradually from $7.3-7.8 \mathrm{~g} / \mathrm{cm}^{3}$ down to $5.9-6.3 \mathrm{~g} / \mathrm{cm}^{3}$. This can be explained by the $\mathrm{SiO}_{2}$ phase formation for the films annealed at $T_{A} \leq 800{ }^{\circ} \mathrm{C}$. However, annealing at higher temperatures could also cause pores formation. To discriminate the origin of the variation of the film density with annealing treatment, analyses of the chemical composition and structure of the films were made by ATR and XRD methods, whereas TEM study was performed to obtain information about the microstructure of the films.

\subsection{ATR infrared spectra of the films}

Among the nondestructive methods used to study thin films, ATR technique holds an important place, since it allows very thin layers to be analyzed.Unfortunately, referenced ATR data for HfSiO materials are not so numerous. The only known data are those regarding the monoclinic $\mathrm{HfO}_{2}$ phase, while for tetragonal and cubic phases of $\mathrm{HfO}_{2}$ and, moreover, for $\mathrm{HfSiO}_{4}$ they are not available in the case of thin films. The interpretation of experimental data obtained for high-k silicate materials is usually based on the comparison of infrared spectra obtained for amorphous $\mathrm{SiO}_{2}$ and $\mathrm{HfO}_{2}$, and their transformation due to an increase of the high- $\mathrm{k}$ material contribution. Information about the crystalline or amorphous nature of the layers can be extracted from the peak shape and the position of the band(s). Usually, $\mathrm{Hf}-\mathrm{O}$ vibration bands are located in the range of $600-800 \mathrm{~cm}^{-1}[36,37]$.

When crystalline $\mathrm{HfO}_{2}$ phase is present in the layer, the welldefined peaks are detected at $770-780 \mathrm{~cm}^{-1}$ and $675-685 \mathrm{~cm}^{-1}$, the first peak being the signature of the monoclinic $\mathrm{HfO}_{2}$ phase $[36,37]$. The observation of only one broad band with a maximum around $690-700 \mathrm{~cm}^{-1}$ was usually attributed to the amorphous nature of the layers $[16,17,36]$.

ATR experiments have been performed on the same pure and Si-rich layers described above. The presence of two main vibration bands in the range of $600-800 \mathrm{~cm}^{-1}$ and $960-1260 \mathrm{~cm}^{-1}$ was revealed for pure $\mathrm{HfO}_{2}$ layers (Fig. 2). The first band corresponds to the $\mathrm{Hf}-\mathrm{O}$ vibrations, whereas the second one is due to $\mathrm{Si}-\mathrm{O}$ vibrations. Its presence is caused by a $\mathrm{SiO}_{x}$ interfacial layer $[1,2,4,8,16,17]$, whereas the shape and peak position depend on its thickness and composition [37].

It is known that continuous random network of $\mathrm{SiO}_{2}$ consists of corner-coordinated $\mathrm{SiO}_{4}$ tetrahedra and a disorder of amorphous structures comes from the changes of $\mathrm{Si}-\mathrm{O}-\mathrm{Si}$ bond angle. Usually, $\mathrm{SiO}_{2}$ leads to four main peaks in the mid-infrared range coming mainly from motion of oxygen atoms. Under specific conditions several LO and TO phonons of Si-O bond can be detected in the $450-1350 \mathrm{~cm}^{-1}$ spectral range: at $1076 \mathrm{~cm}^{-1}\left(\mathrm{TO}_{3}\right)$ and $1256 \mathrm{~cm}^{-1}\left(\mathrm{LO}_{3}\right)$, at $1160 \mathrm{~cm}^{-1}$ $\left(\mathrm{TO}_{4}\right)$ and $1200 \mathrm{~cm}^{-1}\left(\mathrm{LO}_{4}\right)$, at $810 \mathrm{~cm}^{-1}\left(\mathrm{TO}_{2}\right)$ and $820 \mathrm{~cm}\left(\mathrm{LO}_{2}\right)$ as

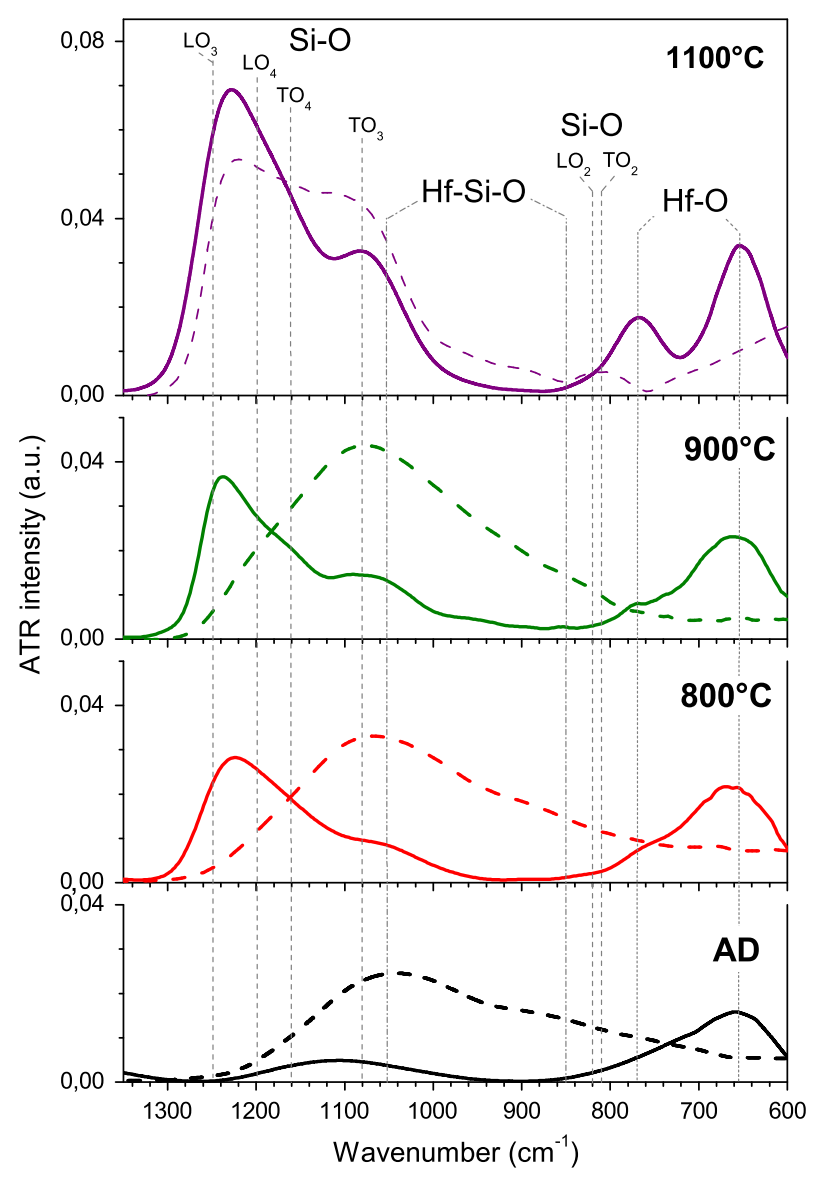

Fig. 2. ATR spectra of as-deposited (AD) and annealed at different temperatures $\mathrm{HfO}_{2}$ (solid lines) and HfSiO (dashed lines) samples. Annealing temperatures are mentioned in the figure, annealing time is $15 \mathrm{~min}$.

well as at $457 \mathrm{~cm}^{-1}\left(\mathrm{TO}_{1}\right)-507 \mathrm{~cm}^{-1}\left(\mathrm{LO}_{1}\right)[38,39]$. The decrease of $\mathrm{SiO}_{2}$ layer thickness to a nanometer scale is accompanied by a shift of the peak positions of all vibration bands to lower wavenumbers as well as by a decrease of the intensity of $\mathrm{TO}_{4}-\mathrm{LO}_{4}$ phonons that are usually considered as a feature of the disordering of $\mathrm{SiO}_{2}$ matrix [39]. In the case of $\mathrm{LO}_{3}$ and $\mathrm{TO}_{3}$ phonons, this shift is about $25-30 \mathrm{~cm}^{-1}$ [40]. However, the detection of $\mathrm{LO}_{3}$ phonon is usually considered as an evidence of the formation of perfect $\mathrm{Si} / \mathrm{SiO}_{2}$ interface [41] and the spectral shift of $\mathrm{LO}_{3}$ and $\mathrm{TO}_{3}$ peak positions towards higher wavenumbers confirms the formation of a stoichiometric silicon oxide layer and increase of its thickness $[17,37]$.

Annealing treatment of pure $\mathrm{HfO}_{2}$ layers results in the different behaviours of $\mathrm{Si}-\mathrm{O}$ and $\mathrm{Hf}-\mathrm{O}$ vibration bands. Thus, initial broad $\mathrm{Si}-\mathrm{O}$ band, centred at about $1100 \mathrm{~cm}^{-1}$ (Fig. 2), shifts towards $1180 \mathrm{~cm}^{-1}$ when $T_{A}=800{ }^{\circ} \mathrm{C}$ accompanied by an appearance of well-defined $\mathrm{LO}_{3}$ and $\mathrm{TO}_{3}$ phonon modes. Upon $T_{A}$ increase, it results in a shift of both of them towards $1230 \mathrm{~cm}^{-1}$ and $1070 \mathrm{~cm}^{-1}$, respectively. This is due to the formation of stoichiometric $\mathrm{SiO}_{2}$ interfacial layer caused by a diffusion of oxygen towards the film/substrate interface. This diffusion is usually considered as a diffusion of the oxygen from environment through the whole volume of high-k layer. However, it was shown for the case of sputtered layers [35], it occurs preferably from the $\mathrm{HfO}_{2}$ layer close to $\mathrm{HfO}_{2} / \mathrm{Si}$ interface. Since the films investigated were annealed in nitrogen atmosphere, the layer closed to $\mathrm{HfO}_{2} / \mathrm{Si}$ interface could be enriched by hafnium caused the formation of oxygen deficient centres. The composition of asdeposited and annealed at $T_{A}=800{ }^{\circ} \mathrm{C}$ layers by energy filtered TEM analysis gave the evidence that $\mathrm{HfO}_{2}$ layer is stoichiometric (not shown here). However, the formation of oxygen-deficient centres 
should occur at higher annealing temperatures due to the formation of monoclinic $\mathrm{HfO}_{2}$ grains observed by ATR investigation. As one can see from Fig. 2, the evolution of the $\mathrm{Hf}-\mathrm{O}$ vibration band is accompanied by the presence of a shoulder at about $770 \mathrm{~cm}^{-1}$ transformed to a well-defined band at higher temperatures. Two separate bands at $770 \mathrm{~cm}^{-1}$ and $680 \mathrm{~cm}^{-1}$ detected for the layers annealed at $1100{ }^{\circ} \mathrm{C}$ confirm the appearance of monoclinic $\mathrm{HfO}_{2}$ phase.

The ATR spectra of as-deposited HfSiO films demonstrate featureless broad band peaked at $1050 \mathrm{~cm}^{-1}$ with a shoulder at about $900 \mathrm{~cm}^{-1}$ and a tail up to $600 \mathrm{~cm}^{-1}$ (Fig. 2). This is the evidence of the formation of a HfSiO matrix. An annealing of the layers at $T_{A}=800{ }^{\circ} \mathrm{C}$ for $15 \mathrm{~min}$ leads to the increase of the intensity as well as to the slight narrowing and to the shift of the broad ATR peak from $1050 \mathrm{~cm}^{-1}$ to $1070 \mathrm{~cm}^{-1}$. On the contrary to pure $\mathrm{HfO}_{2}$ layers, the lower wavenumber part of the ATR spectrum does not change and is still featureless (Fig. 2). Further increase of the temperature up to $T_{A}=900-1000{ }^{\circ} \mathrm{C}$ results in the continuous increase of the peak intensity, shift of the peak position to $1120 \mathrm{~cm}^{-1}$ and the appearance of a shoulder at about $1220 \mathrm{~cm}^{-1}$. A treatment at $T_{A}=1100{ }^{\circ} \mathrm{C}$ causes the narrowing of this vibration band, a redistribution of the intensities of its components and an appearance of the band at about $820 \mathrm{~cm}^{-1}$. All these three bands are ascribed to the $\mathrm{SiO}_{2}$ phase [18]. The formation of an interfacial $\mathrm{SiO}_{2}$ layer is confirmed by the well-defined $\mathrm{LO}_{3}$ phonon whose intensity exceeds the $\mathrm{TO}_{3}$ one (Fig. 2). At the same time, a comparable contribution of $\mathrm{TO}_{3}$ and $\mathrm{TO}_{4}-\mathrm{LO}_{4}$ phonons to ATR spectrum enables us to assume that the increase of the thickness of interfacial $\mathrm{SiO}_{2}$ layers as well as the formation of $\mathrm{SiO}_{2}$ phase inside the film volume is more likely due to the phase separation of the $\mathrm{HfSiO}$ film on $\mathrm{SiO}_{2}$ and $\mathrm{HfO}_{2}$ phases. The latter is confirmed by an increase of the $\mathrm{Hf}-\mathrm{O}$ vibrations' intensity in the range of $600-780 \mathrm{~cm}^{-1}$ at $T_{A} \geq 1000{ }^{\circ} \mathrm{C}$. This broad and featureless band is usually ascribed to amorphous $\mathrm{HfO}_{2}[11,12]$. However, it is hardly believable that such high annealing temperature $\left(1100{ }^{\circ} \mathrm{C}\right.$ ) would lead to an amorphous $\mathrm{HfO}_{2}$ phase.

To get more information about the structure of $\mathrm{HfO}_{2}$ phase, we performed a XRD study of these samples. It is worth to note that the similarity of the ATR spectra obtained for as-deposited and annealed at $T_{A} \leq 900{ }^{\circ} \mathrm{C}$ testifies the thermal stability of the HfSiO layers. The most probable reason explaining this phenomenon is the high flexibility of $\mathrm{Si}-\mathrm{O}$ bonds that allows the amorphous nature of the materials to be kept (similar, for example, to fused silica). However, although $\mathrm{HfSiO}$ can be stable at such annealing temperatures, the slight transformation of Si-O vibration band can be due to the formation of a $\mathrm{SiO}_{2}$ interfacial layer. The latter could occur at lower temperatures (less than $900{ }^{\circ} \mathrm{C}$ ) than that corresponding to the phase separation in $\mathrm{HfSiO}$ film $\left(1000-1100{ }^{\circ} \mathrm{C}\right)$. To clarify this issue, we performed TEM observations of cross-sections of the samples that will be presented below after the analysis of XRD data.

\section{Discussion}

\subsection{XRD study of pure $\mathrm{HfO}_{2}$ and $\mathrm{HfSiO}$ layers}

It is known that XRD patterns, obtained in asymmetric grazing geometry, allow studying the distribution of structural properties across thin layers. The monoclinic $\mathrm{HfO}_{2}$ phase is usually revealed in XRD patterns by the most intense peaks in the range of $2 \theta=15-65^{\circ}$ at $2 \theta=28.37^{\circ}$ and $31.67^{\circ}$ (for (111) planes), $2 \theta=34.34^{\circ}, 34.66^{\circ}$ and $35.55^{\circ}$ (for (200) planes), and $2 \theta=49.59^{\circ}, 50.49^{\circ}$ and $50.91^{\circ}$ (for (220) planes) [42]. The decrease of $\mathrm{HfO}_{2}$ grain sizes results in the broadening of XRD peaks and for the case of amorphous structure only one broad peak in the range of $2 \theta=28-32^{\circ}$ is usually observed $[14,15]$.

The as-deposited pure $\mathrm{HfO}_{2}$ and $\mathrm{HfSiO}$ films show a broad peak in the range of $2 \theta=25-35^{\circ}$ with a maximum intensity at about $2 \theta=32^{\circ}$ (Fig. 3), which is consistent with the amorphous nature of both pure and Si-rich films. The annealing of pure $\mathrm{HfO}_{2}$ film at $800{ }^{\circ} \mathrm{C}$ results in the transformation of the shape of broad XRD peak and an appearance of two overlapped peaks at $2 \theta=28.5^{\circ}$ and $2 \theta=31.7^{\circ}$, that can be considered as a formation of monoclinic phase. This annealing does not lead to the crystallization of $\mathrm{HfSiO}$ films. At higher $T_{A}$, a formation of the $\mathrm{HfO}_{2}$ monoclinic phase is evident by an increase of the observed peaks' intensity with their concomitant narrowing and an appearance of some peaks in the range of $2 \theta=40-65^{\circ}$ (Fig. 3). Annealing of HfSiO film at $1100{ }^{\circ} \mathrm{C}$ results in the appearance of the peaks at $2 \theta=30.3^{\circ}$, $2 \theta=35.3^{\circ}$ and $2 \theta=50.6^{\circ}$, that become to be more pronounced for longer annealing time. These peaks can be ascribed to the (111), (200) and $(220)$ crystalline planes of the tetragonal $\mathrm{HfO}_{2}$ phase. The peak at $2 \theta=59.8^{\circ}$ can be considered as an overlapping of the reflections from (311) and (222) planes of the same phase.

Usually, tetragonal $\mathrm{HfO}_{2}$ phase is observed for ultrathin films, but annealing treatment at temperatures as high as $800{ }^{\circ} \mathrm{C}$ favors its transformation to monoclinic one [43]. However, in our case, longer annealing treatment (up to $30 \mathrm{~min}$ ) at $1100{ }^{\circ} \mathrm{C}$ results in the increasing of the intensities of observed XRD peaks only and does not lead to an appearance of other peaks. This can be an evidence of thermal stability of the tetragonal $\mathrm{HfO}_{2}$ phase in our samples. Since it has higher dielectric constant in comparison with that of monoclinic one, such a film can be used as a gate material for the structures that need high-temperature annealing process such as some nanomemory structures with embedded Si nanoparticles [44].

The analysis of optical properties of the HfSiO layers showed a decrease of their refractive index with annealing treatment. Regarding the structural properties, the phase separation is confirmed by the ATR spectra, whereas the crystallization of $\mathrm{HfO}_{2}$ phase is demonstrated by the XRD data. Since an increase of $n$ is expected with the $\mathrm{HfO}_{2}$

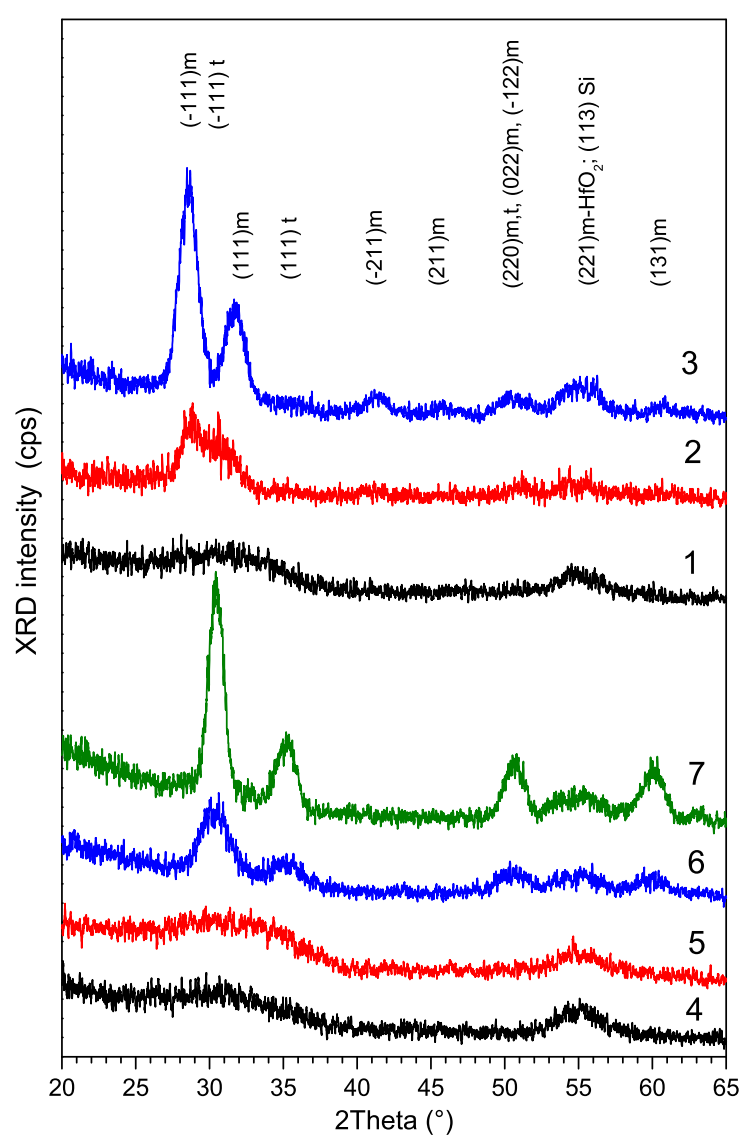

Fig. 3. XRD patterns measured for pure $\mathrm{HfO}_{2}(1-3)$ and $\mathrm{HfSiO}(4-7)$ layers: as-deposited $(1,4)$ and annealed at $T_{A}=800{ }^{\circ} \mathrm{C}(2,5)$ and $1100{ }^{\circ} \mathrm{C}(3,6,7)$ for $15 \mathrm{~min}(1-6)$ and $30 \min (7)$ 
crystallization, we concluded that the refractive index of HfSiO films decreases continuously due to an increasing contribution of the $\mathrm{SiO}_{2}$ phase. At the same time, neither ATR nor XRD studies can reveal unambiguously where the $\mathrm{SiO}_{2}$ phase is located, i.e. at film/substrate interface or embedded in the film volume. However, based on these results and on the estimate of the film density, we can admit the presence of $\mathrm{SiO}_{2}$ phase inside the volume of $\mathrm{HfSiO}$ layer. The latter will be confirmed by TEM observations of as-deposited and annealed films.

\subsection{TEM observation}

TEM images of cross-sections of as-deposited and annealed samples are shown in Fig. 4a. As-deposited samples are homogeneous, smooth enough (roughness does not exceed $1 \mathrm{~nm}$ ) and do not have thick interfacial layer (the thickness being lower than $1 \mathrm{~nm}$ ). These observations corroborate the results obtained by fitting of ellipsometry spectra. The increase of the annealing temperature up to $900{ }^{\circ} \mathrm{C}$ leads to the increase of total film thickness. However, this occurs not only due to the increase of the interfacial $\mathrm{SiO}_{2}$ layer thickness, but also due to the expansion of HfSiO film itself (Fig. 4b). The appearance of bright and dark alternated lines parallel to the film/substrate interface is seen. This can be explained by the Hf segregation process, whereas the film remains amorphous (Fig. 4b).

Further increase of annealing temperature up to $1100{ }^{\circ} \mathrm{C}$ results in the formation of a thicker $\mathrm{SiO}_{2}$ interfacial layer (up to $5 \mathrm{~nm}$ ) as well as a higher contrast between bright and dark regions (Fig. 4b,c). They correspond to $\mathrm{SiO}_{2}$-rich and $\mathrm{HfO}_{2}$-rich phases that are an evidence of the HfSiO phase separation. Besides, the crystallites appear in the dark regions as demonstrated by Fig. 4c. The formation and crystallization
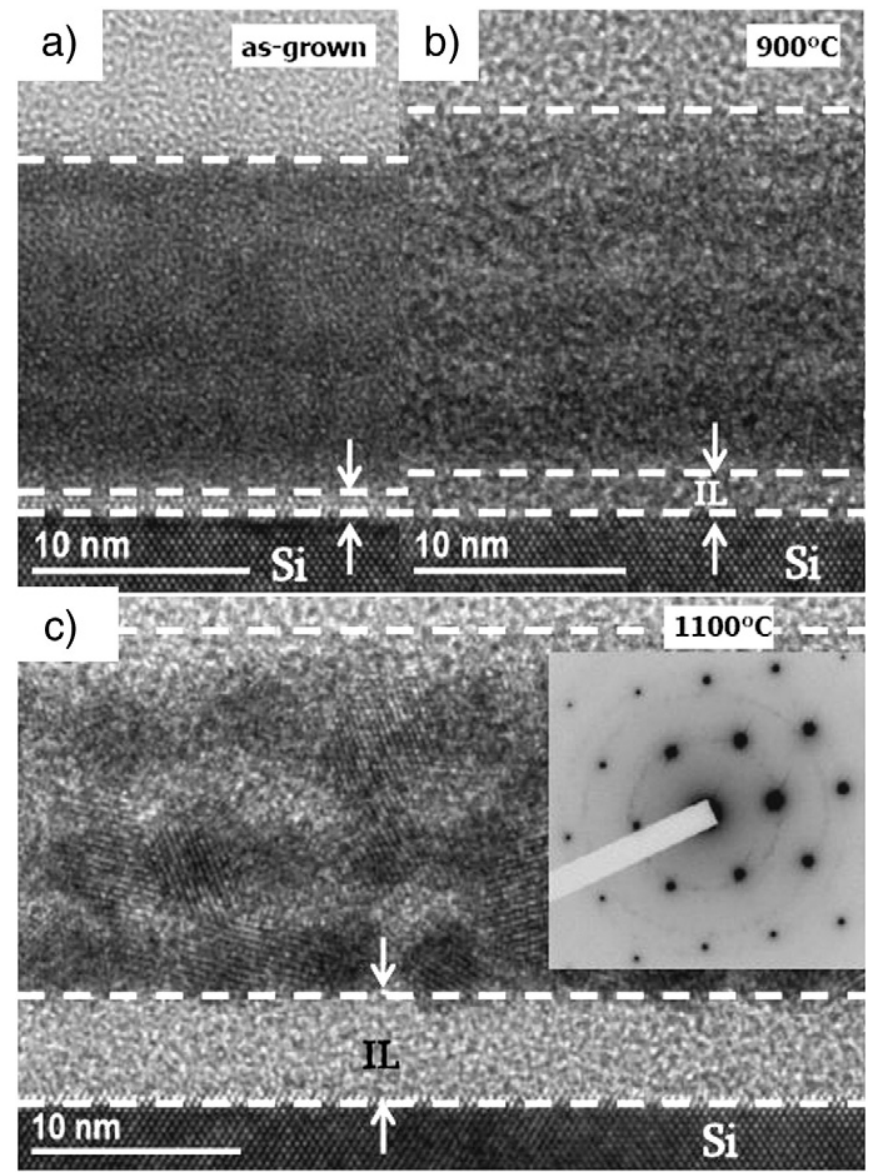

Fig. 4. TEM cross-sections of HfSiO layer taken for as-deposited (a), annealed at $900{ }^{\circ} \mathrm{C}$ (b) and $1100^{\circ} \mathrm{C}(\mathrm{c})$ in nitrogen flow for $15 \mathrm{~min}$. Electron diffraction pattern is shown for the sample annealed at $1100{ }^{\circ} \mathrm{C}$. IL is interfacial $\mathrm{SiO}_{2}$ layer. of $\mathrm{HfO}_{2}$ phase usually leads to the increase of the film density. At the same time the appearance of $\mathrm{SiO}_{2}$ phase results in the decrease of the film density and can be considered as a main reason of the decrease of the total density of the HfSiO film upon annealing.

It is known that thick pure $\mathrm{HfO}_{2}$ has usually the monoclinic phase, whereas tetragonal and cubic phases appear at $1670-2200{ }^{\circ} \mathrm{C}$ [35] When the layer thickness decreases down to a nanometer scale, the presence of the tetragonal phase can be observed in pure $\mathrm{HfO}_{2}$ layers [36]. However, it transforms easily to the monoclinic one at moderate temperatures [36]. The analysis of crystallized $\mathrm{HfO}_{2}$ phase of $\mathrm{HfSiO}$ films was also performed. The inset in Fig. 4c presents a typical selected area electron diffraction (SAED) pattern corresponding to the film and a part of the [110] oriented silicon substrate. Apart from the well defined dots, rising from the silicon substrate, four weak rings appeared. The lattice plane distances estimated from SAED were $2.95 \AA, 1.80 \AA$ and $1.53 \AA$. These distances are compatible with lattice planes of the $\mathrm{HfO}_{2}$ tetragonal phase: $\mathrm{d}_{[111]}=2.95 \AA, \mathrm{d}_{[220]}=1.82 \AA$. and $\mathrm{d}_{[311]}=1.59 \AA$. Thus, TEM observations of HfSiO films show that the tetragonal phase is stable in such films upon annealing at $1100{ }^{\circ} \mathrm{C}$, confirming the XRD study.

\section{Conclusion}

The effect of annealing treatment on the properties of $\mathrm{HfO}_{2}$-based layers has been investigated. It is demonstrated that silicon incorporation into the $\mathrm{HfO}_{2}$ matrix leads to a decrease in the thickness of interfacial layer down to $1 \mathrm{~nm}$ and improves the thermal stability of the layers upon annealing at $900-950{ }^{\circ} \mathrm{C}$. The film density was estimated with respect to annealing temperature. Its decrease with temperature is explained by a phase separation of $\mathrm{HfSiO}$ on $\mathrm{HfO}_{2}$ and $\mathrm{SiO}_{2}$ phases over its volume and the increase of the contribution of the latter with annealing. The formation of the $\mathrm{HfO}_{2}$ tetragonal phase was also revealed. The latter was found to be stable offering a possibility to use such $\mathrm{HfSiO}$ materials for microelectronic applications, for example, for nanomemory structures with embedded $\mathrm{Si}$ nanoparticles requiring high-temperature annealing. The formation of the Si-rich/Hf-rich multilayer structure upon annealing treatment was observed.

\section{Acknowledgments}

This work is supported by the French National Research Agency (ANR) through Nanoscience and Nanotechnology Program (NOMAD Project $n^{\circ}$ ANR-07-NANO-022-02) and by the Conseil Régional de Basse Normandie through the CPER project - Nanoscience axe (2007-2013).

\section{References}

[1] G.D. Wilk, R.M. Wallace, J.M. Anthony, J. Appl. Phys. 87 (2000) 484.

[2] G.D. Wilk, R.M. Wallace, J.M. Anthony, J. Appl. Phys. 89 (2001) 5243.

[3] C. Krug, G. Lucovsky, J. Vac. Sci. Technol. A. 22 (2004) 1301.

[4] M. Houssa, L. Pantisano, R. Degraeve, T. Schram, G. Pourtois, S. De Gendt, G. Groeseneken, M.M. Heyns, Mat. Sci. Eng. R 51 (2006) 37.

[5] G. Pant, A. Gnade, M.J. Kim, R.M. Wallace, B.E. Gnade, M.A. Quevedo-Lopez, P.D. Kirsch, A. Gnade, S. Krishnan, Appl. Phys. Lett. 89 (2006) 032904.

[6] M. Gutowski, J.E. Jaffe, Ch.-L. Liu, M. Stoker, R.I. Hegde, R.S. Rai, P.J. Tobin, Appl. Phys. Lett. 80 (2002) 1897

[7] H. Kato, T. Nango, T. Miyagawa, T. Katagiri, K.S. Seol, Y. Ohki, Appl. Phys. Lett. 92 (2002) 1106.

[8] J--H. Kim, V.A. Ignatova, M. Weisheit, Microelectron. Eng. 86 (2009) 357.

[9] S.K. Dey, A. Das, M. Tsai, D. Gu, M. Flyod, R.W. Carpenter, H. De Waard, C. Werkhoven, S. Marcus, J. Appl. Phys. 95 (2004) 5042.

[10] B.K. Park, J. Park, M. Cho, C.S. Hwang, K. Oh, Y. Han, D.Y. Yang, Appl. Phys. Lett. 80 (2002) 2368.

[11] M. Lui, L.Q. Zhu, G. He, Z.M. Wang, J.X. Wu, J.-Y. Zhang, I. Liaw, Q. Fang, I.W. Boyd, Appl. Surf. Sci. 253 (2007) 7869.

[12] K. Yamamoto, S. Hayashi, M. Kubota, M. Niwa, Appl. Phys. Lett. 81 (2002) 2053.

[13] G. He, Q. Fang, L.D. Zang, Mat. Sci. Semicond. Proc. 9 (2006) 870.

[14] L. Pereira, A. Marques, H. Águas, N. Nedev, S. Georgiev, E. Fortunato, R. Martins, Mat. Sci. Eng. B 109 (2004) 89.

[15] L.-P. Feng, Z.-T. Liu, Y.-M. Shen, Vacuum 83 (2009) 902.

[16] L. Khomenkova, C. Dufour, P.-E. Coulon, C. Bonafos, F. Gourbilleau, Mater. Res. Soc. Symp. Proc. 1160 (2009) 69-72. 
[17] L. Khomenkova, C. Dufour, P.-E. Coulon, C. Bonafos, F. Gourbilleau, Nanotechnology 21 (2010) 095704.

[18] L. Khomenkova, J. Cardin, X. Portier, F. Gourbilleau, Nanotechnology 21 (2010) 285707

[19] M.R. Visokay, J.J. Chambers, A.L.P. Rotondaro, A. Shanware, Appl. Phys. Lett. 80 (2002) 3183.

[20] G.-M. Rignanese, J. Phys. Condens. Matter 17 (2005) R357.

[21] D. Fischer, A. Kersch, Appl. Phys. Lett. 92 (2008) 012908.

[22] Ch.-K. Lee, E. Cho, H.-S. Lee, Ch.S. Hwang, S. Han, J. Phys. Condens. Matter 78 (2008) 012102.

[23] E. Cockayne, J. Appl. Phys. 103 (2008) 084103.

[24] D. Tsoutsou, G. Apostolopoulos, S.F. Galata, P. Tsipas, A. Sotiropoulos, G. Mavrou, Y. Panayiotatos, A. Dimoulas, A. Lagoyannis, A.G. Karydas, V. Kantarelou, S. Harissopoulos, J. Appl. Phys. 106 (2009) 024107.

[25] P. Majumder, G. Jursich, C. Takoudis, J. Appl. Phys. 105 (2009) 104106.

[26] K. Tomida, K. Kita, A. Turiumi, Appl. Phys. Lett. 89 (2006) 142902.

[27] R. Beyers, J. Appl. Phys. 56 (1984) 147.

[28] http://www.horiba.com/scientific/products/ellipsometers/software/.

[29] S. Charvet, R. Madelon, F. Gourbilleau, R. Rizk, J. Appl. Phys. 85 (1999) 4032.
[30] O. Buiu, W. Davey, Y. Lu, I.Z. Mitorvic, S. Hall, Thin Solid Films 517 (2008) 453.

[31] D.A.G. Bruggeman, Ann. Phys. 416 (1935) 636

32] A.R. Forouhi, I. Bloomer, Phys. Rev. B 34 (1986) 7018

[33] G.E. Jelisson Jr., F.A. Modine, Appl. Phys. Lett. 69 (1996) 371.

[34] T. Tan, Zh. Liu, H. Lu, W. Liu, H. Tian, Opt. Mater. 32 (2010) 432.

[35] R. Jiang, E.Q. Xie, Z.F. Wang, J. Mater. Sci. 42 (2007) 7343

[36] N.V. Nguyen, A.V. Davydov, D. Chandler-Horowitz, M.F. Frank, Appl. Phys. Lett. 87 (2005) 192903.

[37] M.M. Frank, S. Sayan, S. Dörmann, T.J. Emge, L.S. Wielunski, E. Garfunkel, Y.J. Chabal, Mat. Sci. Eng. B 109 (2004) 6.

[38] C.T. Kirk, Phys. Rev. B 38 (1988) 1255.

[39] P. Lange, J. Appl. Phys. 66 (1989) 201.

[40] H. Ono, T. Ikarashi, K. Ando, T. Kitano, J. Appl. Phys. 84 (1998) 6064.

[41] J.E. Olsen, F. Shimura, J. Appl. Phys. 66 (1989) 1353.

[42] JCPDS No.78-0050.

[43] J. Tang, F. Zhang, P. Zoogman, J. Fabbri, S.-W. Chan, P. Zhu, L.E. Brus, M.L Steigerwald, Adv. Funct. Mater. 15 (2005) 1595.

[44] M. Perego, G. Seguini, C. Wiemer, M. Fanciulli, P.-E. Coulon, C. Bonafos, Nanotechnology 21 (2010) 055606. 